\title{
USO DO REJEITO DE FLOTAÇÃO DE MINÉRIOS ITABIRÍTICOS COMO AREIA DE MOLDAGEM PARA FUNDIÇÃO DE PEÇAS EM ALUMÍNIO*
}

\section{Resumo}

Sávio José de Oliveira ${ }^{1}$ Ricardo Augusto Martins Figueiredo Leandro Moreira Carneiro ${ }^{3}$ Maria Aparecida Pinto 4 Cláudio Batista Vieira ${ }^{5}$

Gil Ribeiro Vilela Neto ${ }^{6}$

Neste trabalho foram caracterizados dois tipos de rejeitos arenosos, provenientes do processo de flotação do minério de ferro, com o intuito de aplicá-los na fundição de peças de alumínio. A caracterização foi conduzida de duas formas. Primeiro foram realizados os ensaios de caracterização científica, adotados pela indústria de fundição, de modo a avaliar as propriedades dos rejeitos. E, finalmente, os rejeitos foram misturados com aglomerantes para a fabricação de moldes de fundição por dois diferentes processos de moldagem: processo de moldagem de cura a frio e processo de moldagem em silicato de sódio/ $\mathrm{CO}_{2}$. Os dois tipos de rejeito, que diferem na granulometria, se mostraram adequados para uso na indústria de fundição de alumínio, apresentaram propriedades adequadas e foi possível produzir peças sem defeitos.

Palavras-chave: Fundição; Areia de Fundição; Caracterização; Rejeito Arenoso de Flotação; Alumínio.

\section{USE OF THE FLOTATION TAILINGS FROM THE CONCENTRATION PROCESS OF BANDED IRON FORMATION AS A MOLDING SAND FOR FOUNDRY OF ALUMINUM PARTS}

\section{Abstract}

In this work, two types of sandy tailings from the iron ore flotation process were characterized, in order to apply them to the casting of aluminum parts. The characterization was conducted in two ways. First the scientific characterization tests were carried out, adopted by the foundry industry, in order to evaluate the properties of the tailings. Finally, tailings were mixed with binders for the manufacture of casting molds by two different molding processes: cold box molding process and sodium silicate $/ \mathrm{CO}_{2}$ molding process. The two types of tailings, which differ in grain size, were suitable for use in the aluminum casting industry, presented adequate properties and it was possible to produce pieces without defects.

Keywords: Foundry; Sand Casting; Sand Characterization; Sandy Tailings Flotation Aluminum.

1 Engenharia Metalúrgica, Engenheiro, Mestrando, REDEMAT, Universidade Federal de Ouro Preto, Ouro Preto, MG, Brasil.

2 Engenharia de Minas, Mestre, REDEMAT, Universidade Federal de Ouro Preto, MG, Brasil.

3 Engenharia Metalúrgica, Graduando, Estudante, Departamento de Metalurgia e Materiais, Escola de Minas, Universidade Federal de Ouro Preto, Ouro Preto, MG, Brasil.

4 Engenharia Metalúrgica, Doutora, Professora, Departamento de Metalurgia e de Materiais, Escola de Minas, Universidade Federal de Ouro Preto, Ouro Preto, MG, Brasil.

5 Engenharia Metalúrgica, Doutor, Professor, Departamento de Metalurgia e de Materiais, Escola de Minas, Universidade Federal de Ouro Preto, Ouro Preto, MG, Brasil.

6 Engenharia Metalúrgica, Mestre, Engenheiro, Engenheiro de Desenvolvimento Tecnológico, Samarco Mineração S.A, Belo Horizonte, MG, Brasil. 


\section{INTRODUÇÃO}

Areia de sílica é um termo industrial utilizado para a areia com um alto percentual de grãos de quartzo. Quartzo é o cristal de sílica mais comum e o segundo mais abundante mineral na superfície da Terra. É encontrado em quase todos os tipos de rocha ígneas, metamórficas e sedimentares [1].

A indústria de fundição consome grandes volumes de areia para a produção de peças por meio de diferentes processos de fabricação. Nestes processos são fabricados moldes feitos de areia ligada com aglomerantes onde será vazado o metal líquido. A areia silicosa é o tipo de areia mais utilizada em fundição, não só por ser mais facilmente encontrada, como também por possuir características que permitem sua boa utilização nas fundições.

Para serem utilizadas em fundição, estas areias têm que apresentar determinadas características para atender às condições do processo. Dentre estas características, pode-se citar, por exemplo, areias em faixas granulométricas variadas, uniformidade nos grãos, baixa reatividade química com os metais, refratariedade e possibilidade de reaproveitamento após o uso.

No processo de beneficiamento mineral de itabiritos tem-se a geração de dois tipos de rejeitos com características químicas e físicas diferentes. O primeiro é um material muito fino e argiloso, denominado lama, que é proveniente da etapa de deslamagem. O segundo é um material fino, predominantemente silicoso, denominado rejeito arenoso, proveniente do processo de flotação. Este rejeito arenoso é constituído basicamente de sílica e partículas muito finas de óxido de ferro.

Existem vários estudos e pesquisas, realizados por diversos institutos no Brasil, sobre o reaproveitamento dos rejeitos gerados no processo de beneficiamento do minério de ferro itabirítico [2-12]. Alguns estudos propõem a utilização do rejeito como matéria-prima para vidros, esmaltes cerâmicos, argamassas, pisos intertravados e etc., mas não há estudos sobre a utilização do rejeito arenoso como areia de fundição.

Neste trabalho objetiva-se realizar o estudo de caracterização de dois tipos de rejeitos arenosos visando a aplicação destes na indústria de fundição de alumínio como areia base para confecção de moldes de areia.

\section{MATERIAIS E MÉTODOS}

Foram utilizados dois tipos de rejeitos arenosos, os quais foram fornecidos pela Samarco Mineração S.A. Os rejeitos diferem entre si pela granulometria. Por motivo de praticidade adotou-se nesse trabalho a classificação areia fina e areia muito fina para os dois rejeitos, em função dos módulos de finura determinados para cada um deles. O planejamento dos experimentos realizados neste trabalho está esquematizado no fluxograma da Figura 1. Na primeira etapa, foram realizados os ensaios de caracterização científica dos rejeitos e na segunda etapa foram produzidos moldes utilizando os rejeitos nos processos de moldagem com resina de cura a frio e moldagem com silicato de sódio/ $\mathrm{CO}_{2}$, para a fabricação de peças em liga de alumínio silício. 


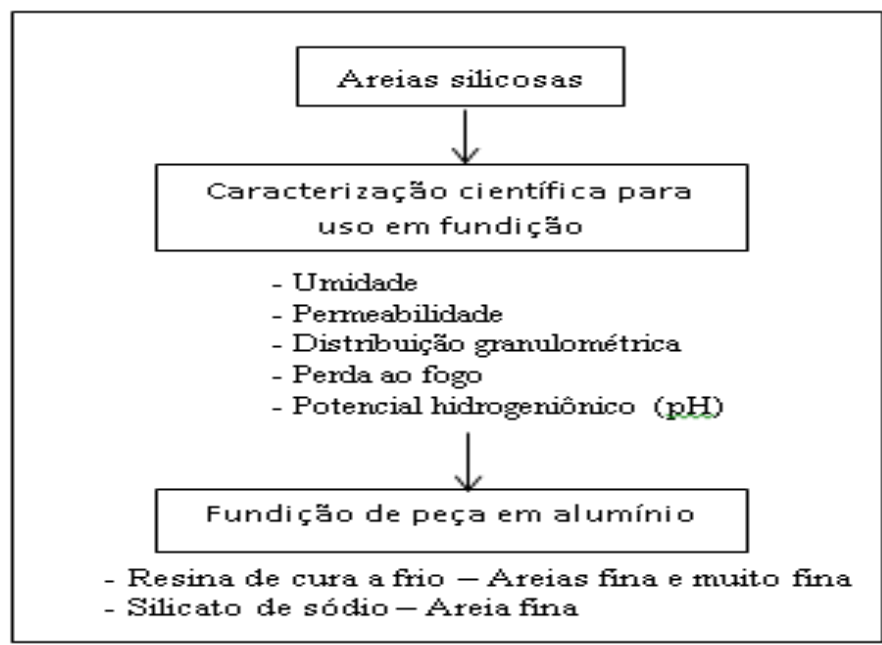

Figura 1 - Planejamento de Experimentos

\subsection{Caracterização Científica}

- Umidade. O ensaio de umidade consiste em submeter uma amostra previamente pesada a um aquecimento para eliminar a umidade e determinar a fração desta presente na amostra. A realização do ensaio se deu de acordo com a recomendação CEMP-105 [13].

- Permeabilidade. O ensaio de permeabilidade visa determinar a capacidade que a areia base tem em permitir a passagem de ar através dos vazios entre os grãos. $O$ ensaio consiste basicamente em fazer passar ar por um corpo de prova de areia compactada. A realização do ensaio foi feita de acordo recomendação CEMP-080 [14].

- Distribuição Granulométrica No ensaio de distribuição granulométrica fazse passar por um conjunto de peneiras uma amostra de $50 \mathrm{~g}$ areia por $15 \mathrm{~min}$ a fim de separá-la em diferentes frações granulométricas. Ao final do peneiramento, cada fração retida nas peneiras é pesada. Foram feitos três ensaios em cada areia para determinação da média. Os ensaios, realizados conforme a recomendação CEMP-081 [15].

- Perda ao Fogo. O ensaio de perda ao fogo é usado para determinação de matérias voláteis presentes na amostra de areia. É realizado submetendo as amostras a temperaturas de aproximadamente $950^{\circ} \mathrm{C}$ de modo que as matérias voláteis se desprendam da areia. Ao final do processo de aquecimento, a amostra é pesada e determina-se a massa perdida e, consequentemente, a perda ao fogo. O procedimento para este ensaio é descrito na recomendação CEMP-120 [16].

- Potencial Hidrogeniônico (pH). Para a determinação do pH das amostras, as etapas a serem seguidas constam na recomendação CEMP-121 [17].

\subsection{Fundição das Peças em Liga de Alumínio pelo Processo de Resina de Cura a Frio}


O processo resina de cura a frio refere-se a um processo de moldagem no qual a cura do molde se dá em temperatura ambiente. Para a fabricação das peças, a primeira etapa foi a preparação da mistura de areia e aglomerantes (Resina PI, Resina PII e catalisador), segundo CEMP-182 [18]. A etapa seguinte foi a produção dos moldes e dos machos, com as misturas de areia fina e areia muito fina, previamente preparadas, para a fabricação da peça suporte de eixo.

Com os moldes prontos, os machos foram posicionados, as caixas de moldar foram fechadas. O metal líquido foi vazado nos moldes após cerca de uma hora de cura da resina. A liga de alumínio foi vazada nos moldes a uma temperatura de $800^{\circ} \mathrm{C}$. Depois de aguardado determinado tempo para que todo o metal se solidificasse e resfriasse, as caixas foram separadas e as peças solidificadas foi retiradas dos moldes. Em seguida, foram feitas a remoção dos canais, massalotes e rebarbação das peças, seguido de um jateamento com jato de areia.

\subsection{Fundição da Peça em Liga de Alumínio pelo Processo de Silicato de Sódio/ $/ \mathrm{CO}_{2}$}

No processo de moldagem com areia aglomerada com silicato de sódio/ $\mathrm{CO}_{2}$, as etapas de preparação do molde e do macho, de acordo com a recomendação CEMP-087 [19], consistem na mistura da areia com o silicato de sódio e moldagem da peça, seguida da passagem do gás $\mathrm{CO}_{2}$ através do molde, provocando uma reação química do silicato de sódio com o gás que resultará no endurecimento da mistura. Neste processo foi utilizada somente a areia fina.

A gasagem foi realizada fazendo-se passar o gás $\mathrm{CO}_{2}$ por orifícios no molde e no macho a uma vazão constante de $101 / \mathrm{min}$ durante 20 s por orifício. Após a preparação do molde e colocação do macho, foi feito o vazamento da liga de alumínio nas mesmas condições do processo anterior.

Após solidificação e resfriamento, foi feita a limpeza e rebarbação da peça, nas mesmas condições do processo anterior.

\section{RESULTADOS E DISCUSSÃO}

Os resultados serão apresentados seguindo a ordem das análises, ou seja, iniciando-se pela caracterização científica e, por fim, os resultados do processo de fabricação das peças em liga de alumínio em escala de bancada.

\subsection{Caracterização Científica}

A Tabela 1 apresenta os resultados dos ensaios de caracterização científica realizados para as duas areias: areia fina e areia muito fina.

Tabela 1 - Resultados da caracterização científica das areias

\begin{tabular}{ccccc}
\hline & Umidade & Perda ao Fogo & Perm. (AFS) & $\mathrm{pH}$ \\
\hline Areia fina & $0,08 \%$ & $0,74 \%$ & 121 & 6,61 \\
\hline Areia muito fina & $0,04 \%$ & $1,54 \%$ & 47 & 5,75 \\
\hline
\end{tabular}

A umidade é uma propriedade importante a ser avaliada, pois acima de determinado teor, gera defeitos nas peças fabricadas e complicações no processo de moldagem. No ensaio de umidade realizado nas areias obteve-se uma média de umidade da ordem de $0,08 \%$ para a areia fina e $0,04 \%$ para a areia muito fina, 
valores que estão abaixo de $0,1 \%$, estabelecido como limite máximo de especificação para areia de fundição, segundo CEMP E-01 [20].

A perda ao fogo das areias está de acordo com os valores normalmente empregados para uma areia de fundição que são da ordem de $3 \%$, segundo D'Elboux [21]. Valores elevados de perda ao fogo podem gerar gases em excesso na cavidade do molde ocasionando defeitos nas peças fundidas em função do aprisionamento dos gases no metal.

A análise da permeabilidade da areia base é essencial para avaliar o comportamento da areia no processo de fundição bem como identificar possíveis defeitos decorrentes de baixa permeabilidade. Segundo CEMP E-01 [20], uma areia padrão para ensaios de fundição deve possuir uma permeabilidade base da ordem de 110AFS a 140AFS. Foram realizados três ensaios de permeabilidade em cada areia, obtendo-se uma média dos valores. A areia fina apresentou um valor de permeabilidade que é coerente com o valor indicado para uma areia de fundição (121AFS). Para a areia muito fina, a permeabilidade encontrada está abaixo daquela tida como ideal para uma areia de fundição (47AFS). Este resultado é reflexo da grande quantidade de finos presentes nesta areia, os quais prejudicam a passagem dos gases através da mesma.

De acordo com Fernandes [22], o pH da areia deve estar de acordo com o tipo de aglomerante empregado mas, geralmente é indicado que esteja em torno de 7. Para o processo fenólico-uretânico (resina utilizada neste trabalho), uma areia ácida pode provocar reação com o catalisador, neutralizando parte deste e provocando perda de resistência da areia.

Os resultados da análise granulométrica das areias são apresentados na Tabela 2.

Tabela 2 - Resultados análise granulométrica das areias

\begin{tabular}{ccccc}
\hline \multicolumn{5}{c}{ Parâmetros das Areias } \\
\hline Mreia fina & Mód. finura AFS & Classificação & Conc. granulom. & Finos $(<105 \mu \mathrm{m})$ \\
\hline Areia muito fina & 109 & Areia fina & $91 \%$ & $1,98 \%$ \\
\hline
\end{tabular}

Analisando os resultados da análise granulométrica apresentados na Tabela 2 , observa-se que a areia muito fina possui uma grande quantidade de finos $(41 \%)$ na sua constituição, fazendo com que o valor do módulo de finura seja alto, 109AFS.

Para uma areia de fundição não é desejável que esta possua uma quantidade considerável de finos (fração abaixo de $0,105 \mathrm{~mm}$ ), pois as partículas finas, por possuírem maior área superfícial específica, necessitam de maior quantidade de aglomerante para promover a união dos grãos da areia. A presença de finos em excesso também prejudica a permeabilidade da areia. De acordo com Fernandes [23], o teor de finos indicado para areias de fundição é da ordem de $1 \%$ ou menor. Neste caso, a areia fina possui uma porcentagem de finos mais adequada para fundição.

A partir da análise granulométrica, também é interessante avaliar a concentração granulométrica das areias, ou seja, a maior porcentagem retida em três peneiras consecutivas. A Figura 2 apresenta o gráfico das porcentagens retidas em cada peneira para as duas areias analisadas. 


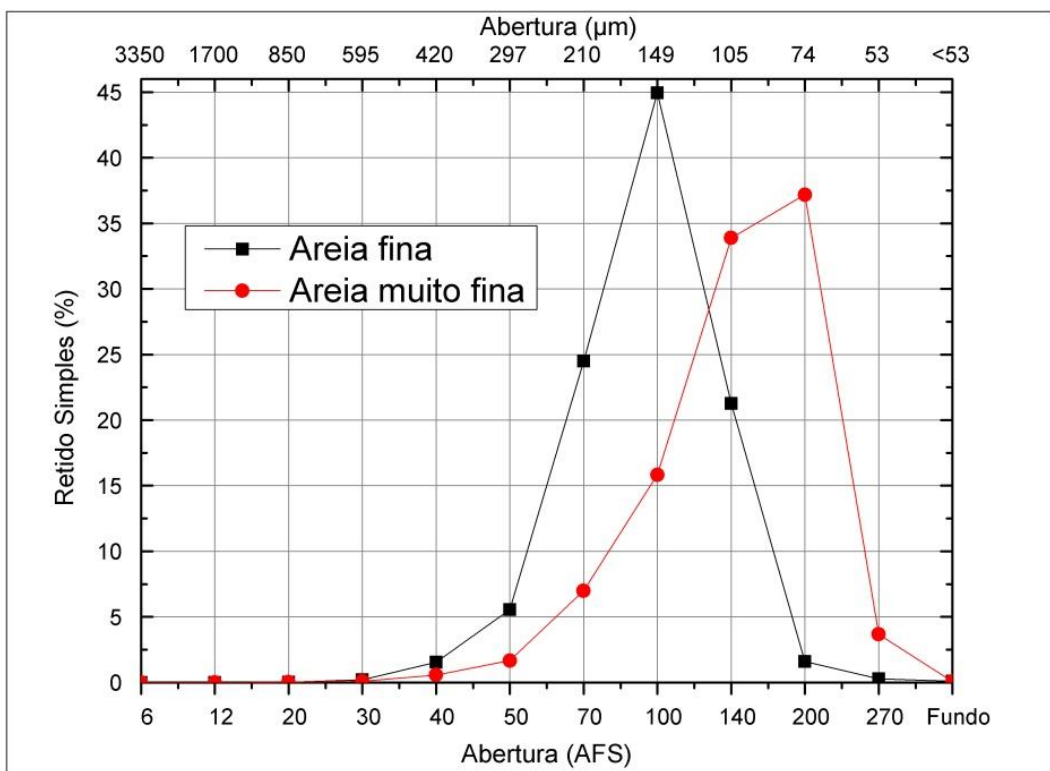

Figura 2 - Porcentagem retida nas peneiras em função das aberturas

Observa-se, a partir da Figura 2, que ambas as areias possuem alta concentração granulométrica. Porém para a areia fina os grãos concentram-se em faixas de tamanhos maiores quando se compara à areia muito fina, a qual apresenta uma maior concentração nas aberturas de $105 \mu \mathrm{m}, 149 \mu \mathrm{m}$ e $210 \mu \mathrm{m}$. Para areia de fundição é aconselhável que a concentração granulométrica seja da ordem de $70 \%$ retida em três peneiras consecutivas da série padrão [23]. Uma propriedade da areia que é influenciada pela concentração granulométrica é a fluidez, ou seja, a capacidade da areia em escoar para dentro do molde. A fluidez da areia aumenta com o aumento da concentração granulométrica [23]. Como visto na Tabela 2, as areias em estudo possuem uma concentração granulométrica acima de $80 \%$ fazendo com que esta propriedade esteja de acordo com os valores indicados.

\subsection{Moldagem e Fundição de Peças em Liga de Alumínio com a Areia Fina}

A areia fina mostrou-se eficiente para a moldagem utilizando os processos de moldagem em resina de cura a frio e silicato de sódio/ $\mathrm{CO}_{2}$. A areia produziu misturas que conferiram boa resistência aos moldes, facilidade de retirada dos modelos e, após a fusão, boa colapsibilidade. Os moldes produzidos apresentaram boa qualidade e uma resistência adequada para a fundição não ocorrendo quebras e defeitos que prejudicassem a qualidade das peças. As Figuras 3 e 4 mostram as cavidades dos moldes produzidos com a areia fina pelos processos resina de cura a frio e silicato de sódio/ $\mathrm{CO}_{2}$, respectivamente. Para a mistura de areia fina com a resina de cura a frio, observou-se que o tempo de vida de banca, ou seja, o tempo disponível para a moldagem é relativamente curto, sendo necessária maior agilidade na produção do molde ou a utilização de menor quantidade de catalisador. 


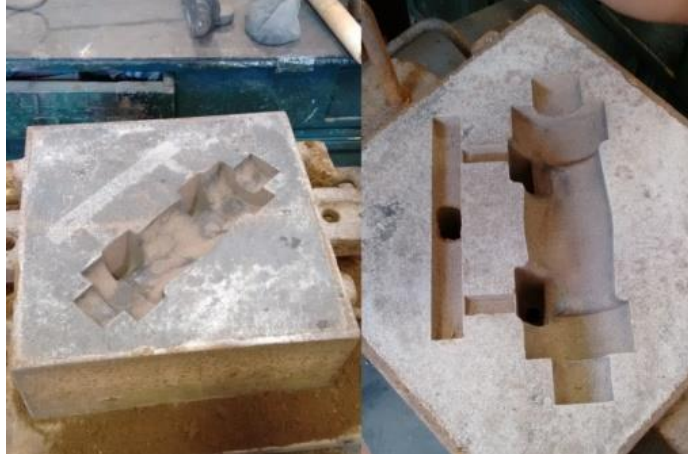

Figura 3 - Molde de areia fabricado com areia fina pelo processo resina de cura a frio

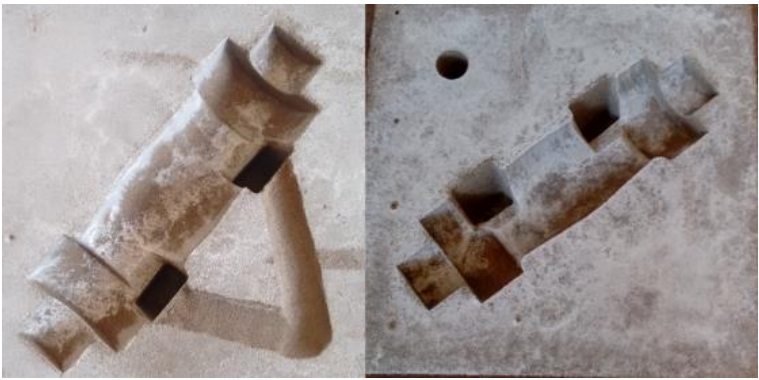

Figura 4 - Molde de areia fabricado com areia fina pelo processo silicato de sódio/ $\mathrm{CO}_{2}$

Dos moldes produzidos com a areia fina foram obtidas duas peças em liga de alumínio, vazado nos moldes das Figuras 3 e 4 . As peças obtidas são apresentadas nas Figuras 5 e 6.

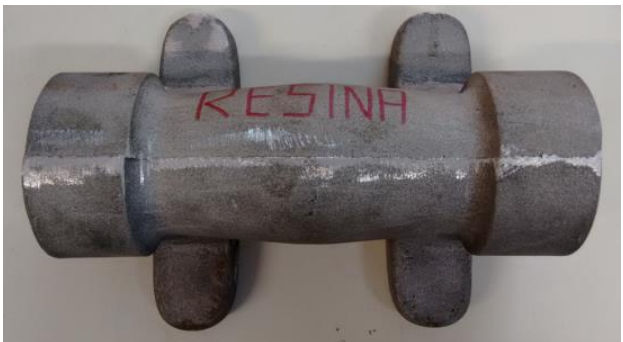

Figura 5 - Peça de alumínio - resina de cura a frio (areia fina)

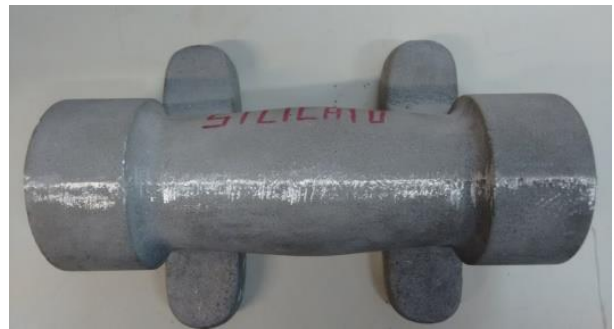

Figura 6 - Peça de alumínio - silicato de sódio (areia fina)

$\mathrm{Na}$ peça produzida pelo processo de resina de cura a frio, Figura 5, não se observou nenhum defeito relacionado ao molde ou macho que reprovasse 0 desempenho da areia no processo, sendo que a peça foi fabricada com relativa facilidade.

Da mesma forma, no processo silicato de sódio/ $\mathrm{CO}_{2}$ não houve problemas na peça relacionados ao molde ou macho, mostrando que a areia é adequada para este uso. A peça produzida por esse processo apresentou qualidade semelhante à qualidade da peça produzida com a mesma areia pelo processo resina de cura a frio. 


\subsection{Moldagem e Fundição de Peças em Liga de Alumínio com a Areia Muito Fina}

Apesar da grande quantidade de finos presentes nesta areia, foi possível realizar a confecção do molde utilizando a mesma proporção de resina adotada para a areia fina. $O$ molde produzido apresentou resistência mecânica suficiente para receber o metal líquido. A Figura 7 mostra o molde produzido com esta areia.

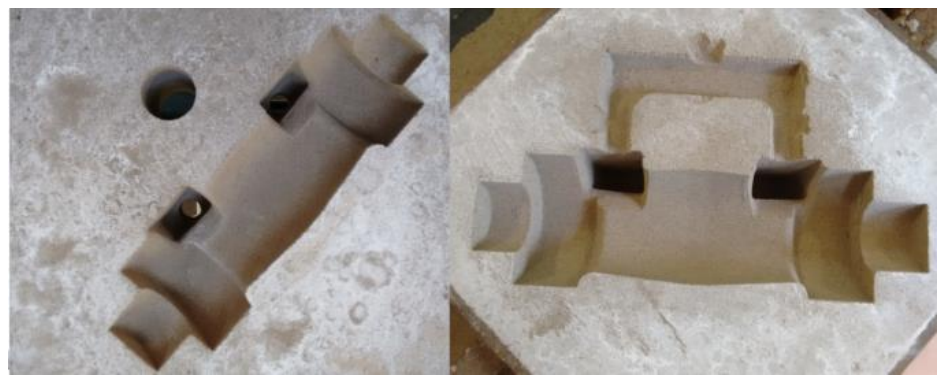

Figura 7 - Molde de areia fabricado com areia muito fina pelo processo resina de cura a frio

Para essa areia também foi observado um tempo de vida de banca curto no processo resina de cura a frio, fazendo com que após preparada, a mistura tivesse que ser levada rapidamente às caixas de moldar. Porém esta característica não resultou em problemas no molde.

A Figura 8 mostra a peça final obtida após processo de desmoldagem, retirada dos canais, rebarbação e jateamento.

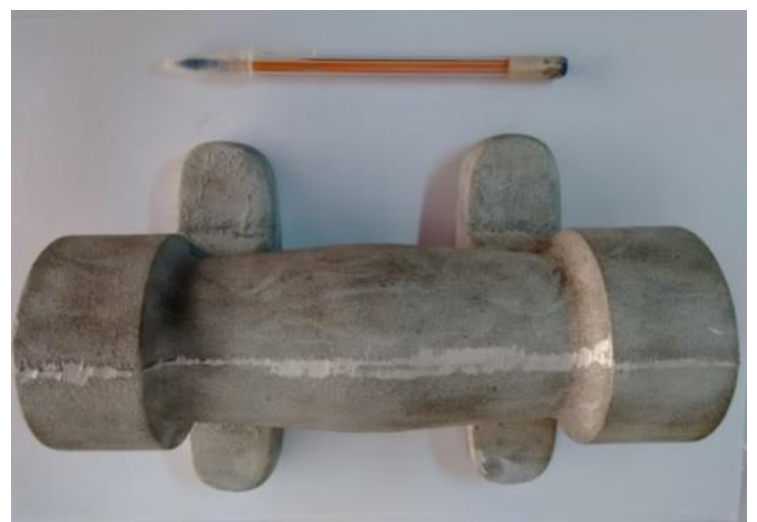

Figura 8 - Peça de alumínio - resina de cura a frio (areia muito fina)

A peça não apresentou nenhum defeito causado pelo molde ou macho. Por possuir um módulo de finura mais elevado, resultando em menos espaços vazios entre os grãos da areia, aliado à maior tensão superficial do alumínio quando comparada à do aço, por exemplo, a areia muito fina proporcionou uma peça com excelente qualidade superficial.

Devido à boa qualidade superficial, a etapa de acabamento consistiu basicamente de corte dos canais, jateamento e um simples lixamento com uma lixadeira elétrica para retirar algumas rebarbas presentes na linha de divisão da peça.

Contudo, observou-se a presença de porosidade na parte posterior da peça ocasionada por falha na acomodação/compactação da areia nessa região durante a moldagem, por se tratar de regiões do modelo de acesso mais difícil e sendo que a moldagem foi feita manualmente. O detalhe deste defeito é mostrado na Figura 9. 

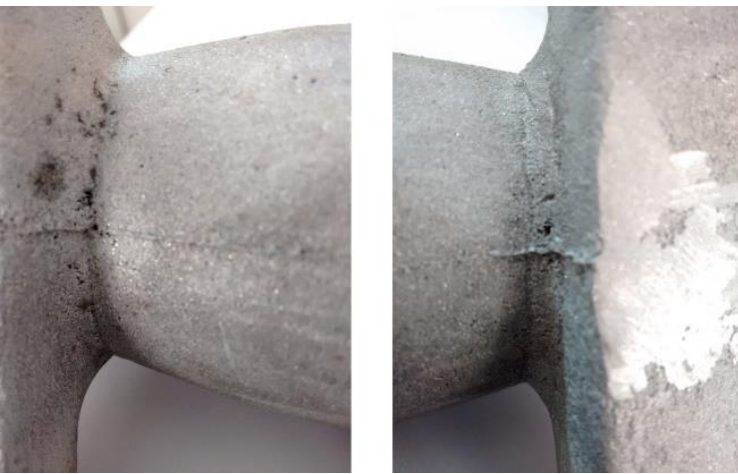

Figura 9 - Porosidade na peça provocada por problemas durante a moldagem

Analisando as três peças produzidas, verificou-se que os respectivos moldes e machos apresentaram boa resistência mecânica e todas elas apresentaram bom acabamento superficial, com destaque para a peça produzida com a areia muito fina. A Figura 10 mostra as peças produzidas na qual areia A é a areia fina e areia B é a areia muito fina.

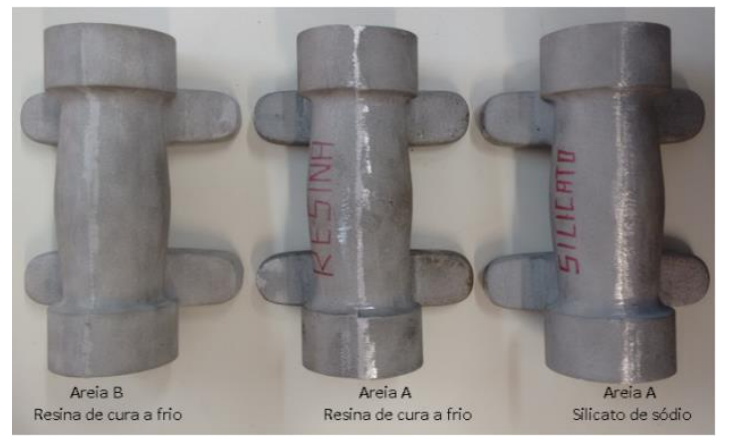

Figura 6 - Peças de alumínio produzidas com os rejeitos arenosos

\section{CONCLUSÕES}

A partir dos ensaios científicos e de fundição em escala de bancada realizados com as areias, provenientes do rejeito arenoso, foi possível ter uma visão geral do comportamento das areias submetidas ao processo de fundição.

Pela caracterização científica dos materiais, observa-se que algumas propriedades como umidade, perda ao fogo e potencial hidrogeniônico não comprometem 0 desempenho das areias, porém, da análise granulométrica percebe-se a grande quantidade de finos contidos na areia muito fina, finos estes que, geralmente, não são desejáveis para uma areia de fundição dado que diminuem a permeabilidade e provocam um maior consumo de aglomerante para que se obtenha um mesmo valor de resistência mecânica para uma areia normalmente usada em fundição.

$\mathrm{Na}$ moldagem e produção das peças em liga de alumínio pelo processo de moldagem com resina de cura a frio, obteve-se sucesso na confecção dos moldes e machos das peças. As peças produzidas não apresentaram defeitos em decorrência do uso do rejeito arenoso como matéria-prima para moldagem e macharia. O mesmo comportamento foi observado utilizando o processo de moldagem e macharia com as areias aglomeradas com silicato de sódio/ $\mathrm{CO}_{2}$. Nos dois processos, as areias retornaram moldes, machos e peças com boa qualidade, indicando que é possível a 
utilização do rejeito arenoso de forma eficaz para os processos de moldagem e macharia na produção de peças fundidas em alumínio.

É preciso considerar também que a produção de peças em ligas de alumínio impõem esforços menores ao molde e machos, devido à menor temperatura de fusão e à baixa densidade do metal. Dito isto, e pelos resultados promissores obtidos neste trabalho, fica claro que ambas as areias têm potencial para serem utilizadas como areia de fundição na produção de peças em ligas de alumínio, originando produtos de qualidade.

\section{Agradecimentos}

À UFOP, Escola de Minas, DEMET, Samarco Mineração S.A, Fundação Gorceix e FEOP.

\section{REFERÊNCIAS}

1 ARIFFIN, K. S. What is silica. Mineral Perindustrian. 2004;1-7.

2 CAMPANHA, A. Caracterização de rejeito de minério de ferro para uso em pavimentação. 2011. 86 p. Dissertação (Mestrado em Engenharia Civil) Universidade Federal de Viçosa, Viçosa, 2011.

3 FREIRE, C. B. Utilização de resíduos da exploração do itabirito em pavimentos intertravados. 2012, 189 p. Tese (Doutorado em Engenharia de Materiais)- Rede Temática de Materiais- Universidade Federal de Ouro Preto, Ouro Preto, 2012.

4 MARTINS, P. F. F. Obtenção de sílica de elevada pureza a partir do rejeito de flotação de um minério de ferro itabirítico. 2016. 128 p. Tese (Doutorado em Ciência e Tecnologia das Radiações, Minerais e Materiais). Centro de Desenvolvimento da Tecnologia Nuclear, Belo Horizonte, 2016.

5 MELO, V. A. R. Utilização de resíduo arenoso gerado na exploração do itabirito em substituição ao agregado miúdo natural para preparação de argamassa de cimento Portland. Ouro Preto - MG, 2012, 74 p. Dissertação (Mestrado em Engenharia de Materiais) - REDEMAT (Rede Temática em Engenharia de Materiais), UFOP - Universidade Federal de Ouro Preto, 2012.

NOCITI, D. M. Aproveitamento de rejeitos oriundos da extração de minério de ferro na fabricação de cerâmicas vermelhas. 2011. 111 p. Dissertação (Mestrado em Engenharia Mecânica). Faculdade de Engenharia - Universidade Estadual Paulista, Guaratinguetá, 2011.

7 PEREIRA JÚNIOR, S. S. Desenvolvimento de argamassas contendo resíduos arenosos de mineração e estudo de suas propriedades visando sua utilização. Belo Horizonte - MG, 2011, 145f. Dissertação (Mestrado em Ciência e Tecnologia das Radiações, Minerais e Materiais) - CDTN - Centro de Desenvolvimento da Tecnologia Nuclear, 2011.

8 PINTO, S. S. S. Caracterização das propriedades físicas e mecânicas de misturas de diferentes tipos de rejeito para aplicação em pavimentos. 2013. 81 p. Dissertação (Mestrado em Engenharia Civil) Universidade Federal de Viçosa, Viçosa, 2013.

9 SAMARCO. Aproveitamento de subprodutos do processo de concentração do minério de ferro da Samarco Mineração S.A. em outros setores industriais. Ouro Preto, 2009. 
10 SOUZA, R.E. Utilização de resíduo de mineração para obtenção de madeira plástica. Ouro Preto - MG, 2013, 63f. Dissertação (Mestrado em Engenharia de Materiais) - REDEMAT (Rede Temática em Engenharia de Materiais), UFOP - Universidade Federal de Ouro Preto, 2013.

11 TAVARES, P. H. C. P. Obtenção de pigmentos de óxido de ferro a partir da lama gerada no beneficiamento de itabirito. 2012. 133p. Tese (Doutorado em Engenharia de Materiais). REDEMAT (Rede Temática em Engenharia de Materiais), UFOP - Universidade Federal de Ouro Preto, 2012

12 TOLENTINO, M. V. C. Estudo da viabilidade técnica do aproveitamento do resíduo arenoso da mineração do itabirito. 2010. 104 p. Dissertação (Mestrado em Ciência e Tecnologia das Radiações, Minerais e Materiais). CDTN - Centro de Desenvolvimento da Tecnologia Nuclear, Belo Horizonte, 2010.

13 ASSOCIAÇÃO BRASILEIRA DE FUNDIÇÃO - ABIFA. CEMP 105: Materiais para Fundição - determinação do teor de umidade. São Paulo: ABIFA, 2015. $2 p$.

14 ASSOCIAÇÃO BRASILEIRA DE FUNDIÇÃO - ABIFA. CEMP 080: Areia base para fundição - determinação da permeabilidade. São Paulo: ABIFA, 2015. $4 \mathrm{p}$.

15 ASSOCIAÇÃO BRASILEIRA DE FUNDIÇÃO - ABIFA. CEMP 081: Materiais para fundição - determinação da distribuição granulométrica, módulo de finura e teor de finos em materiais granulares. São Paulo: ABIFA, 2015. 5p.

16 ASSOCIAÇÃO BRASILEIRA DE FUNDIÇÃO - ABIFA. CEMP 120: Materiais para fundição - determinação da perda ao fogo. São Paulo: ABIFA, 2015. 2p.

17 ASSOCIAÇÃO BRASILEIRA DE FUNDIÇÃO - ABIFA. CEMP 121: Materiais para fundição- determinação do pH. São Paulo: ABIFA, 2015. 3p.

18 ASSOCIAÇÃO BRASILEIRA DE FUNDIÇÃO - ABIFA. CEMP 182: Resina cura a frio para fundição - preparação da mistura padrão utilizando batedeira planetária. São Paulo: ABIFA, 2015. 4p

19 ASSOCIAÇÃO BRASILEIRA DE FUNDIÇÃO - ABIFA. CEMP 087: Silicato de sódio para fundição - preparação da mistura padrão. São Paulo: ABIFA, 2015. 3p.

20 ASSOCIAÇÃO BRASILEIRA DE FUNDIÇÃO - ABIFA. CEMP E-01: Areia padrão para ensaios em fundição. São Paulo: ABIFA, 2015. 3p.

21 D’ELBOUX, F.A. Minimização do descarte de areias de fundição. 2000. 158f. Dissertação (Mestrado em Engenharia de Produção) - Faculdade de Engenharia Mecânica e de Produção, Universidade Metodista de Piracicaba, Santa Bárbara d'Oeste, 2000.

22 FERNANDES, D. L. Areias de fundição aglomeradas com ligantes furânicos. Itaúna: SENAI. DR.MG, 2001. 121p.

23 FERNANDES, D. L. Areias sílico-argilosas sintéticas. Itaúna: SENAI. DR.MG, 2006. 143p. 